\title{
A Literature Review on the Study of the Gender Differences in
}

\section{Language}

\author{
Zhixin Ma \\ School of Foreign Language and Literature, ShanDong University, Jinan 250100, China; \\ Zhixin_ma@163.com
}

Keywords: language and gender, difference, theoretical explanation

\begin{abstract}
Language and gender is an important topic in sociolinguistic studies based on the relative theories and studies about language and gender. This paper is a literature review of the research discoveries both at home and abroad. The western research methods of gender difference in linguistics experience two different periods: the first one is unsystematic study period and the second one is systematical study period. In the past 30 years, the major models on language and gender studies include deficit theory, dominance theory, difference theory, polite theory and construction theory. Besides, it also previses readers the four main contents of language and gender study in China: the introduction and review of theory, the language use strategy, language application ability and conversational style. It also proposes the trend of further study to some degree.
\end{abstract}

\section{Introduction}

Language is the reflection of social cultures. It is also the encyclopedia of social behaviors. Speaking of this, studied on language and gender differences is important and worthful. In many fields of sociolinguistics, it is very necessary to study gender differences in language. The gender study is a cross-disciplinary subject which involving sociology, psychology, ethnology and feminism. With the growth of sociolinguistics and the raising of feminism in the 1960s, the study of differences between language and gender becomes a research hotpot. Many new terms are used, such as “women's language”, “the female register”, "genderlect” and "gender-related language”. This paper is a literature review on the study of the gender differences in language home and abroad.

\section{The Western Research Methods of Gender Difference in Linguistics}

\subsection{The Unsystematic Study Period.}

During the first period, the investigation of language and gender first appears in Greek and Rome, with a hypothesis that the genus in gamma symbolizes the sexes in biology. It dominates in the linguistic theory for a long time which influent some linguists as J.Grinm. During 17 centuries, when the Europeans set up on the American land, "they first encountered the different vocabularies of male and female speech among the Carib Indians, they reported that the different sexes used different languages (Yule, 1985). In 1908, C. Stopes published “The Sphere of 'man': I n relation to that of 'woman' in the Constitution”, which research the use of “man” and "woman” in English laws. F. Mauthener and Jespersen begin to research the European language from the perspective of the gender factor in the language of Southeast Asia. Then the study of language and gender difference of human beings can trace back to 1922 (Jesperson, 1922). Jesperson introduces the appearance and characters of female languages in his book with one independent chapter, including using the euphemism, completing the switch of topic and empty. In other words, though female talks a lot, it is nonsense. In the book Growth and Structure of English Language, Jesperson points that English is the most masculine language which females are familiar with.

\subsection{The Systematical Study Period.}

In systematical study period, sociolinguistic is formed as a marginal subject of linguistic and sociology in American. The research approaches in sociology are used to survey and analyze 
characters of people's daily language. It shows that the gender character influence people's language and behaviors in a certain way. In the 1970s, with the raising of female liberation movement, the gender difference in language attracts people's attention, which promotes the further study of gender question. Some linguistics try to dig out the reasons that causing mistakes in the communications between males and females, such as Lakoff, West Thome, Henle and Bolinger. D. Bolinger (Aspects of Language, 1968; Language the Loaded Weapon, 1980) and M Schulz (The Semantic Derogation of woman, 1975) make great contribution to gender discrimination phenomenon. Besides, there are several works discussing the characters of female's language: R. Brend (Male-Female Intonation Patterns in American English, 1975) and E. Baird (Ses Difference in Group Communication, A Review of Relevant Research, 1976). Besides, D. Spender, an editor of Women's Studies International Quarterly, has published a book named Man Made Language in 1980, which advances many new views. In the past 30 years, the major models on language and gender studies include deficit, dominance, difference, politeness and constructionism.

\subsubsection{The Deficit Theory.}

Robin Lakoff is a major figure of the deficit theory in her book Language and women's place in 1975. In her opinion, language reflects and strengthens the social convention. The difference languages of male and female are the mirror of their different roles in society. The gender difference in language reveals the inequality of females' social status. The inequality in language cannot be eliminated unless there is no inequality in social status and powers. In patriarchal society, male speaking structure is viewed as standards and criterion while female speaking structure is the deviation and intention, which implies that a female indeed.is a imperfection existence in society. Besides, she points that "the defection of female language is the result of role socialization" (Lakoff ,1996). However, with the development of society, the social status and roles of female have witnessed great changes. This point is neglected by Lakoff.

\subsubsection{The Dominance Theory.}

It is D. Zimmer-man, C. West and P. Fishman who hold the view of dominance theory. They think that females have no social positions so that females, who live in a passive position, are always be dominated. For example, when females are talking with the opposite sex, they are always be interrupted and be limited to a certain topic and time. According to their studies, in terms of talking method and strategy, the males tend to a strong domination and prefer to control the topic and talking turns so that the females are interrupted frequently. The males enjoy their dominant position while talking. Usually when the females are interrupted by males, they always choose the silence instead of fighting it out for the right to speak. The inequality social power and influence lead to the imbalance position in the communication between males and females.

\subsubsection{The Difference Theory.}

According to the difference theory, there is an obvious gender difference in the language due to the different subculture backgrounds of males and females. Goodwin (1980) once conducts a survey between two children groups and draw a conclusion that girls and boys share different group characters. It is consistent with the opinion of folklores that the speaking style of males is tend to hard-edged and competitive while the females are implicit and indirect. Different from Lakoff's view, the culture difference holders point that what important is the different speaking styles of females, not the imperfection of females. Therefore, this theory wins the support of many scholars who study the gender and language, especially the female scholars. It is widely used to explain the misunderstanding during the communication between males and females. American linguist Tannen (1990) points out that the male and females, who come from the same culture background and speak the same language, tend to live in conflicts due to the different customs of using language. Traditionally the male is viewed as a strong person and protector while the female is viewed as the weak and the protected. Therefore, the male and female form their own speaking characters correspond to their social acquirements and expectations. It can be seen from the speaker's tendency, content and ways of expressing. The speaking topic of males is wilder than the females which relates to social, politics, politics and sports. 


\section{The Domestic Research Methods of Gender Difference in Linguistics}

\subsection{The Introduction and Review of Theory.}

The literature about the introduction and review of theory is reflected in the introduction and review of five theories of gender difference in language, including deficit, dominance, difference, politeness and constructionism "(Li Jingwei, 2001). There exist disputes over binary thinking and pluralistic thinking on the study of language and gender today (Li Jingwei, 2002). It also includes the introduction of the gender discrimination and expression of gender difference (Shi Shangshan, Zhang Shanglian, 2006), the empirical study about the male and female speakers during oral communication (Shi Zhuqin, 2007) and reflection of the history of gender factors in linguistics (Zhao Ronghui, 1999).

\subsection{The Language Use Strategy.}

Oxford (1989) find that gender is closely related to the use of learning strategies and the females are more prefer to use learning it. Chen Liping (2005) conducts a survey about the gender difference and the use of conversational strategy of non-English majors using collage Corpus of Spoken English. Zhang Zhaoyi (1996) states the gender difference in conversation mode and strategies. Hou Songshan (1998) observes the difference of communicative task and the influence of the gender difference of commenters. Wang Limei (2008) studies the gender difference of acquisition of communicative strategies of EFL studies.

\subsection{The Language Application Ability and The Conversational Style.}

Yuan Fengshi and Xiao Defa (2003) choose the non-English majors as the study subjects with the use of quantitative research method and conduct a survey about the gender difference and the relationship with score of CET-4. Liu Zhenqian and Shi Yunzhang (2006) search the relationship between reading anxiety of foreign language and gender difference and scores of CET-4. Yu Xueyong (2005) uses the scores of CET-4 as the analysis index to analysis the effect of gender difference to the second language acquisition.

Linguists find that there exists the difference between different genders, including the choose of topic, the way of speaking and discourse amount. Studies about conversational style include $\mathrm{Xu}$ Lisheng (1997), Shi Gengshan and Zhang Shanglian (2004) towards the explanation of speech style and Wang lieqin (2005) towards the advantage and difference of gender characters.

\section{Summary}

In conclusion, language and gender is an important topic in sociolinguistic studies based on the relative theories and studies about language and gender. Due to the various interests, backgrounds and views of researchers, there are many different theories about gender difference in language. Nowadays, the study of gender and language has made great progress and develop towards diversification, dynamic and microscopic verification. Now many researchers begin to pay more attention to the collection of corpus and the influence of local culture and people's social psychological factors. Besides, some researchers switch their eyes from the purely theoretical problems to application to guide people's daily life, avoiding the misunderstanding and miscommunication caused by the different language customs.

\section{References}

[1]. Cameron, Deborah. The Language-gender Interface: Challenging Co-optation [A]. Bergvall, V. L. Bing. J. M. and Freed, A. F. Rethinking Language and Gender Research [C]. New York: Longman, 1996, p. 31-53.

[2]. Cameron, Deborah. Rethinking Language and Gender Studies: Some Issues for the 1990s [A]. Mills, Sara. Language and Gender: Interdisciplinary Perspectivs [C]. New York: Longman,1995, P. 31-44.

[3]. Fishman, P. M. Interaction: the work women do [J]. Social Problems. Vol.25 (1978). P. 397-406. 
[4]. George Yule. The Study of Language. [M]. Cambridge University Press,1985, p. 242.

[5]. Goodwin, M. H. Directive-response Speech Sequences in Girls’ and Boys’ Task Activities [C]. New York: Praeger,1980, p. 157-173.

[6]. Holmes. Janet Women Men and Politeness [M]. New York: Longman, 1995, p. 12.

[7]. Jesperson, Otto. Language: it's nature, development and origin. [M]. London: Allen \& Unwin, 1922.

[8]. Lakoff Robin. You Say What You Are Acceptability and Gender-related Language [A]. Allen H. B. and Linn. M. D. Dialect and Language Variation [C]. Academic Press, 1996. Inc:45-48

[9]. Tennen Deborah. You Just Don’t Understand [M]. New York: Ballantiine Books,1990, p.12.

[10]. Dai Weidong. Summary of the Analysis of the Gender Differences in Speech [J]. Journal of Foreign Languages Vol. 6 (1983), p. 01-05.

[11]. Yang Yonglin. Summary of the Modern Study of Gender Differences in English [J]. Shandong Foreign Language Teaching Journal. Vol. 2(1991):39-50.

[12]. Hou Songshan. (1998). Mission and Impact of Gender on Communicative Strategies [J]. Journal of Pla University of Foreign Languages.Vol.6 (1998), p. 20-25.

[13]. Li Jingwei. Gender Differences in Language and Reasons [J]. Shandong Foreign Language Teaching Journal. Vol.3(1998), p. 12-16.

[14]. Li Jingwei. A Review of Western Language and Gender Studies [J]. Journal of Pla University of Foreign Languages. Vol.1(2001), p. 11-15.

[15]. Shi Zhuqin. A Summary of Research on Language and Gender Differences [J] Foreign Languages Research Vol. 5 (2007), p. 38-42.

[16]. Shi Yunshan, Liu Zhenqian. Foreign Language Reading Anxiety and English Achievement and Gender Relations [J]. Journal of Pla University of Foreign Languages.Vol.2 (2006), p. 59-64.

[17]. Shi Gengshan, Zhang Shanglian.. A Literary Review of Language and Gender Studies in China [J]. Foreign Language Education. Vol.3 (2006), p. 24-27.

[18]. Wang Lieqin.. The Advantages and Difference : Gender Factors in Verbal Communication [J]. Foreign Language Education. Vol. 5(2005): 21-25.

[19]. Xu Lisheng. A Study of Gender Differences in Speech Style [J]. Foreign Language. Vol.1 (1997), p. 43-48.

[20]. Yang Yongzhong. Review on the Pattern of Gender Discourse [J]. Language Teaching and Linguistic Studies. Vol.2 (2001), p. 56-65.

[21]. Zhao Ronghui. Language and Gender Studies Reviewed. [J]. Foreign Languages Research. Vol.3 (1999), p. 25-29. 